\title{
Evaluation of the content of a web tool aimed to identify early markers related to fall risk among middle-aged people
}

\author{
Mia Folke ${ }^{1}$ (1) $\cdot$ Anna Åkerberg ${ }^{1,2}$ (1) $\cdot$ Marina Arkkukangas $^{2}$ (D) $\cdot$ Annika Kärnsund $^{3} \cdot$ Mikael Johnsson $^{4}$ (1)
}

Received: 6 July 2020 / Accepted: 21 September 2020 / Published online: 28 September 2020

(C) The Author(s) 2020

\begin{abstract}
Today, the health care sector has no test for early age-related deterioration in physical ability. The aim of this study was to evaluate questionnaires, videos and physical tests whose task will be to identify early markers related to an increased fall risk in middle-aged people. If the person is aware of deficits in physical ability related to fall risk, the person can then use that knowledge to perform relevant training that can strengthen the physical ability related to fall risk. Self-efficacy for balance and strength, physical ability related to fall risk and body composition were measured for 36 middle-aged test participants. This study shows that the tested physical exercises were useful for self-assessment of physical ability. Impairment in physical ability could not be identified solely with measurement of body composition, walking speed, questions, videos that show adjustments that are common in people with impaired balance, or an extended version of the Short version of Activities-specific Balance Confidence scale. This study indicates that a combination of questionnaires, videos and physical exercises can evaluate physical ability and act as a method to identify early markers related to increased fall risk. The questionnaire, videos and physical exercises can be implemented in a web tool that could make persons aware that they have decreased physical ability regarding fall risk or that they needlessly make physical compensations when performing daily activities and thus are missing opportunities to strengthen their physical ability every day.
\end{abstract}

Keywords Fallprevention $\cdot$ Physical tests $\cdot$ Early markers $\cdot$ Physical exercise $\cdot$ Middle-age $\cdot$ Physical ability

\section{Introduction}

Falls constitute the most common and severe threat to people's health worldwide, and studies report that falls are the leading cause of injury for people of almost all ages $[1,2]$. Falls are the most common work incident, with approximately 11,000 falls annually [3]. Of these falls, approximately 8000 are ground level falls, and falls became more common among older workers.

Mia Folke

mia.folke@mdh.se

1 School of Innovation, Design and Engineering, Mälardalen University, Västerås, Sweden

2 Research and Development in Sörmland, Eskilstuna, Sweden

3 Center for Clinical Research, Västerås, Sweden

4 Department of Mechanical Engineering, Blekinge Institute of Technology, Karlskrona, Sweden
Since a person's ability to maintain his or her important balance and strength functions over time decreases [4], it is of utmost importance to address these functions even at an early age to prevent falls. Current recommendations for physical activity include, to some extent, strength and balance exercises [5]; however, these recommendations are not sufficient to address the great problem associated with falls. Evidence has convincingly shown exercises targeting strength (including power) and balance to be effective in preventing falls if performed regularly and in a structured manner by older adults $[6,7]$.

With this knowledge of the importance of these physical functions and the deterioration of these functions with age, interventions targeting adults in the transition towards old age are of the utmost importance, indicating that prevention efforts should start in early life. However, tests to identify decreased physical function that can serve as early markers for increased fall risk in middle-aged people have been sparsely investigated.

Today, the health care sector has no test for early agerelated deterioration in physical ability [8]. However, 
questionnaires and various physiological measurements are used to estimate fall risk in elderly persons who are believed to be at risk of fall or have already fallen. Walk speed is one parameter measured to identify fall risk [9]. Other parameters are muscle mass [10-12] and physical exercises used to measure strength and balance. With these tests for older people and the knowledge that strength (including power) and balance are important parameters to avoid fall in mind, the aim of this study was to evaluate questionnaires, videos and physical exercises to determine whether they can be useful in identifying early markers related to an increased fall risk. These tests are meant to make the person aware of deficits in physical ability related to fall risk. Therefore, the person can use this knowledge and perform relevant training that strengthens the physical ability related to fall risk. To find such early markers, middle-aged persons, 45-55 years old, were recruited as test participants. Since it is of importance to have a test that can identify early markers, it is important that the individuals can perform the test and evaluate the results by themselves to not burdening the health care system with the tests. Therefore, the possibility of individuals of performing and evaluating the tests by themselves was also studied.

\section{Methods}

\subsection{Development of test methodology}

To increase the overall research quality, the test methodology used in this study was developed in three steps. First, 43 open-ended interview questions were designed to reveal the target groups' prior understanding of physical ability, their concern regarding fall risks, their interest in preventive training for reducing fall risk, and their interest in paying for the test and training instructions. Videos of situations in daily life were recorded. The situations were recorded with each situation performed by a person without any fall-related problem, and the same person performed the activities with different adjustments that are common in people with reduced balance. Second, audio-recorded and transcribed interviews with 11 respondents representing the target group were conducted. In the interviews, the respondents also evaluated what situation they best related to regarding the different video-recorded daily life situations. The purpose was to evaluate both the interview questions' and the videos' relevance and understandability to better understand the target groups' first impressions of a web tool and its implementation potential. Third, based on this prework, the test methodology used in this study was developed and is further described below.

\subsection{Test participants}

A total of 36 middle-aged individuals (12 men and 24 women, age 45-55 years old) with different levels of education in different fields and employed in different kinds of work were recruited by convenient selection for this study. The study was approved by the Swedish Ethical board, Dnr: 2019-00,992.

\subsection{Measured parameters}

Self-efficacy for balance and strength, physical ability related to fall risk and body composition were measured for all 36 test participants. Self-efficacy for balance and strength was measured with subjective tests: interview questions and the identification of videos that best represent the way the test participant performs daily activities. Physical ability related to fall risk was measured with objective tests: walking speed, balance and strength with physical exercises performed by the test participants. Body composition (body weight, muscle mass, body fat) was measured on a Baurer BF 600 scale. All the subjective and objective parameters were measured by the test leader.

\subsection{Subjective test: Interview questions and videos and an expanded version of the ABC- 6 scale}

The test participants were interviewed in the first part of the study protocol with questions about their balance and strength. The interview questions were as follows:

- Do you feel that you have sufficiently good balance to do what you want in daily life?

- How do you think, in general, a person can notice that they have decreased balance in daily life?

- Can you give any example of people you have seen with these decreases in balance?

- Have you noticed any of these problems yourself?

The test participants were shown videos of a person performing daily activities without any problems and of the same person performing the activities with different adjustments that are common in people with reduced balance. After watching the videos, the test participant selected the videos that best represented how he/she performs this everyday activity. The everyday activities in the videos were as follows:

- Going up an escalator.

- Descending a stationary staircase.

- Putting on a sock with no place to sit.

- Walking down a steep slope. 
The test participants were also asked questions from an expanded version of the Short version of Activities-specific Balance Confidence scale, ABC-6 scale [13, 14], which are illustrated in Table 5.

The test participants answered the questions on a scale from $0-100 \% .100 \%$, indicating that they were absolute sure that they could perform the activity asked in the expanded ABC-6 scale without losing balance, to $0 \%$, indicating that they knew that they will lose balance if they performed the activity in the question. The result of the expanded ABC-6 scale is presented as the average percentage across the questions. The questions were as follows:

In terms of percentage, on a scale from 0 to $100 \%$, how sure are you that you can:

- reach for something on your tiptoes without losing balance?

- stand on a chair to reach something without losing balance?

- walk in a crowd/bump into someone without losing balance?

- use an escalator without holding the rail without losing balance?

- walk on an icy sidewalk without losing balance?

- jump over a puddle $(70 \mathrm{~cm})$ without losing balance?

- jump over a ditch $(70 \mathrm{~cm})$ without losing balance?

- walk down a steep slope without losing balance?

- walk on curbstones without losing balance?

- stand on one leg at a time without support and put on your socks without losing balance?

\subsubsection{Objective tests: Physical exercises}

The test participants attempted to perform physical exercises to evaluate which of the exercises they complete and, at the same time, study if the participants can see for themselves if they performed the physical exercise correctly. The test leader noticed the result of each physical exercise and compared it with the test participant's self-assessed estimation of correct performance. The physical exercises were designed to measure walking speed in different directions, strength and balance.

Walking speed was measured by asking the test participant to walk $20 \mathrm{~m}$ at her or his own selected daily walking speed. A walking speed cutoff of $1.0 \mathrm{~m} / \mathrm{s}$ has been used to capture several additional risk factors for falls among communitydwelling elderly and could represent a useful tool for identifying individuals who are vulnerable but not yet disabled [9].

Elderly persons have reduced balance and the ability to do a fast step to stabilize the body if they lose balance [15]. The test participant's ability to walk fast and change directions was measured by asking the test participant to repeat two steps forward and two steps back at six set walking speeds. The same physical exercise with six set walking speeds was also performed by asking the test participant to repeat two steps left and two steps right. These two physical exercises at set walking speeds aimed to represent the Four Square Step Test [16].

Balance was tested by asking each test participant to stand with their feet close to each other in a semitandem and a tandem position for $20 \mathrm{~s}$ each. This balance test is designed for elderly persons [17]. The test participant was also asked to walk on a line with short steps, bringing the heel of the leading foot close to the toe of the other foot on a straight line. More than one step failure was marked as failure to perform the test. The test participant was also asked to stand for 1 min on each leg.

The physical exercises measuring strength included asking the test participant to perform chair squats at 3 set speeds. This physical exercise is a version of the 30-s chair stand test [18]. The test participants also tried to perform lunges and return to the starting position. This physical exercise refers to a test that asks elderly persons to take a big step and come back to the starting position [19]. The test participants also performed this easier test. The test participants also tried to rise from sitting in a chair to stand up on one leg. This test was meant to test whether the test participant had double the strength in the leg needed to stand up with both legs since an older person's ability to maintain strength over time decreases [4]. The stand-up-on-one-leg test also checks balance.

The ability to perform rapid angle torque development in the ankle decreases as the person ages [20]. Toe raises were performed at three different speeds to measure the strength and speed of the feet and ankles.

The unilateral hip bridge endurance test [21] was used to check core stability.

\subsection{Data analysis}

Descriptive statistics were used to study the data.

The physical exercises were studied to determine whether the test participants could see for themselves whether or not they had performed the physical exercise correctly. The test leader determined whether the physical exercise was performed correctly. If the test participant had the same opinion as the test leader, it was counted as the test participant seeing for him- or herself if he/she had performed the physical exercise correctly.

In the rest of the data analysis, only the exercises most of the test participants can see for themselves if they performed correctly were included and only the test leader's opinion on whether it was performed correctly was used.

The number of test participants who failed to complete any of the physical exercises was counted, and the exercise each test participant failed and the corresponding speed was noticed. 
The test participants'.

- body composition (weight, body fat percentage and muscle mass)

- $\quad$ self-selected walking speed

- ownobservations of any reduced balance

- ability to do the daily activities demonstrated on the videos with or without adjustment

- answers to the expanded version of the ABC- 6 scale

was assessed with respect to whether or not the test participants were able to perform the physical exercises.

Windows Excel 2016 was used for data analysis.

\section{Results}

\subsection{Can the test participants evaluate their physical exercise performance for themselves?}

The Toe raises and Unilateral hip bridge endurance test were excluded from the analysis since most of the persons had difficulties determining whether or not they could perform the physical exercises correctly. These physical exercises would not be useful in a system designed to be used by individuals to test their physical ability on their own.
Eight of the 36 test participants had difficult determining whether or not they correctly performed the repeated two steps left and two steps right and two steps forward and two steps back exercises. All eight test participants were able to decide if they performed the physical exercises correctly at lower speeds, but at higher speeds, they were unsure if they had succeeded or not.

\subsection{Can the physical exercises provide early markers related to an increased fall risk?}

All test participants were able to perform the balance tests: standing with their feet close to each other in a semitandem and tandem position for $20 \mathrm{~s}$ each. The test participants also walked in different directions at speeds that corresponded to the Four Square Step Test and performed squats at a speed that corresponded to the 30 -s chair stand test. They were also able to take a large step and return to the starting position and had a walking speed above $1.0 \mathrm{~m} / \mathrm{s}$. Therefore, none of the physical exercises used to identify an increased risk of fall in elderly persons can be used to find any reduction of physical ability related to fall risk for any of the test participants. However, some of the test participants showed a reduction in physical ability related to fall risk as measured with the following exercises.

Thirteen and 15 participants failed to walk the repeated two steps left and two steps right and two steps forward and two

Table 1 Each line in the table represents a test participant who did not perform all the physical exercises correctly. Only failed physical exercises are noted. Therefore, an empty box means that the test participant passed this physical exercise

\begin{tabular}{|c|c|c|c|c|c|c|}
\hline $\begin{array}{l}\text { Speed level } \\
\text { of step two } \\
\text { steps left and } \\
\text { two steps right } \\
\text { (Max level 6) }\end{array}$ & $\begin{array}{l}\text { Speed level } \\
\text { of step two } \\
\text { step forward } \\
\text { and two steps back } \\
\text { (Max level 6) }\end{array}$ & $\begin{array}{l}\text { Number of } \\
\text { missed steps } \\
\text { when walk } \\
\text { on a line }\end{array}$ & $\begin{array}{l}\text { Able to stand } \\
\text { one minute } \\
\text { on one leg }\end{array}$ & $\begin{array}{l}\text { Speed level } \\
\text { of squats } \\
\text { (Max level 3) }\end{array}$ & $\begin{array}{l}\text { Able to } \\
\text { perform one } \\
\text { lunges }\end{array}$ & $\begin{array}{l}\text { Able to stand } \\
\text { up on one } \\
\text { leg from } \\
\text { chair }\end{array}$ \\
\hline \multirow[t]{2}{*}{1} & 1 & & & 2 & & \\
\hline & 5 & 3 & & & & Failed \\
\hline 4 & 2 & & & 2 & & Failed \\
\hline \multirow[t]{2}{*}{3} & 2 & & & & & Failed \\
\hline & 5 & & Failed & & & \\
\hline 3 & 4 & & & & & \\
\hline \multicolumn{7}{|l|}{5} \\
\hline & 3 & & & & & Failed \\
\hline 1 & 1 & & Failed & & & \\
\hline 4 & 3 & & & & & \\
\hline 4 & 3 & & & & & Failed \\
\hline 4 & 3 & & & & & Failed \\
\hline 1 & 1 & 2 & Failed & 2 & Failed & Failed \\
\hline 5 & 4 & & & & & \\
\hline 5 & 3 & & & & & \\
\hline 2 & 5 & & & & & \\
\hline
\end{tabular}


Fig. 1 Number of test participants among the 36 total test participants who were not able to perform the exercises at all speeds

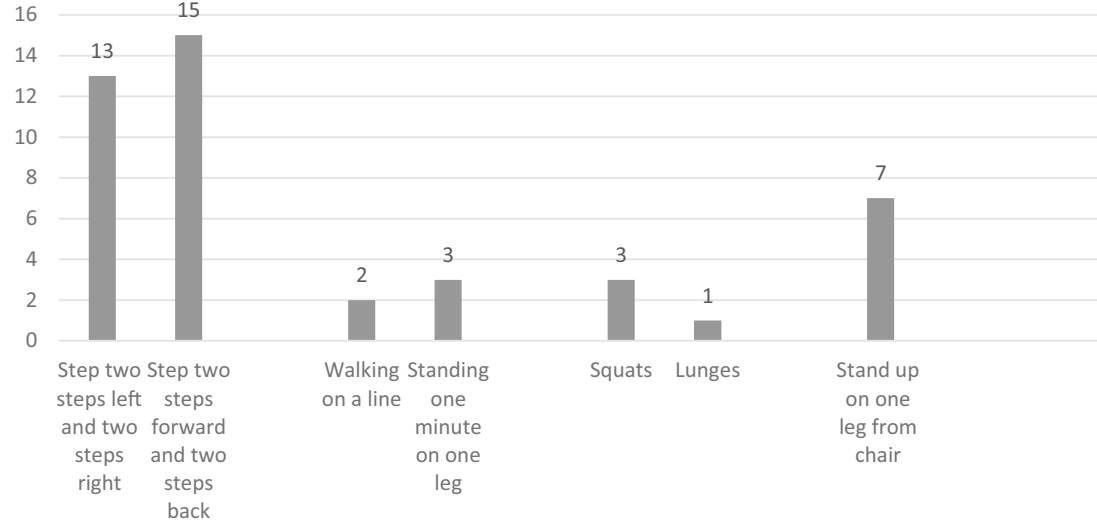

steps back tests, respectively, at any of the selected walking speeds (Fig. 1). Additionally, in some of the other exercises, some of the test participants were not able to complete the whole test, Fig. 1. For the 16 test participants who did not perform all the physical exercises correctly, the failed physical exercises for each subject are summarized in Table 1.

\subsection{Can body composition or self-selected walking speed indicate an early reduction in physical ability related to fall risk?}

The average body weight for all 36 test participants was $75.4 \mathrm{~kg}$. The average body fat percentage for all 36 test participants was $30.5 \%$. The lowest body fat percentage was $16.5 \%$. The highest body fat percentage was $52.2 \%$. The body composition along with body weight, body fat percentage and muscle mass percentage for all test participants are presented in Table 2.

The average self-selected walking speed for all 36 test participants was $1.7 \mathrm{~m} / \mathrm{s}$. The lowest walking speed was $1.3 \mathrm{~m} / \mathrm{s}$, and the highest walking speed was $2.7 \mathrm{~m} / \mathrm{s}$. The walking speed for all test participants is presented in Table 2.

\subsection{Can subjective parameters indicate an early reduction in physical ability related to an increased fall risk?}

All test participants reported that their balance was good enough to perform daily activities. When asked how they think imbalance starts, seven of the 36 test participants revealed that they noticed imbalances themselves. Reported difficult activities/incidents that they noticed themselves included stumbling on carpets, falling down stairs twice, performing fast movements such as walking sideways, and unsteadiness when stepping up on a chair, trying to reach something high up, and trying to dress and stand on one leg.

Table 3 summarizes the number of participants who reported incidents where they noticed any reduced balance and the number of participants who could or could not complete all the physical exercises. Nineteen of the 36 test participants did not notice any balance problems and were able to perform all the physical exercises. Five test participants reported activities/incidents related to reduced balance and were not able to perform all the physical exercises. One person was able to perform all the physical exercises but had noticed imbalance in sport activities. Eleven test participants were not able to perform all the physical exercises but had not reported any activities/incidents related to reduced balance.

Table 4 summarizes the number of participants who could or could not complete all the physical exercises and the number of participants that said they performed the activities shown in the videos with or without adjustment. Thirteen of the 36 test participants said that they performed the activities on the videos without adjustment and were able to perform all the physical exercises. Thirteen of the 36 test participants said that they performed the activities with some of the adjustments shown in the videos and were not able to perform all the physical exercises. Seven test participants who said that they performed the activities with some of the adjustments shown in the videos were able to perform all the physical exercises.

Table 2 Body weight $(\mathrm{kg})$, body fat $(\%)$, muscle mass $(\%)$ and walking speed $(\mathrm{m} / \mathrm{s})$ for the test participants who did and did not perform all the physical exercises correctly. Mean (min-max) values noted

\begin{tabular}{lllll}
\hline & Body weight $(\mathrm{kg})$ & Body fat $(\%)$ & Muscle mass (\%) & Walking speed (m/s) \\
\hline Able to perform all the physical exercises & 66.6 & 25,1 & 34.0 & 1.62 \\
& $(54.1-85.6)$ & $(16,5-43,3)$ & $(27.0-42.5)$ & $(1.28-2.69)$ \\
Not able to perform all the physical exercises & 82.4 & 35.0 & 32.5 & 1.65 \\
& $(62.7-97,6)$ & $(21.0-52.2)$ & $(23.3-40.1)$ & $(1.28-2.13)$ \\
\hline
\end{tabular}


Table 3 Summary of the number of test participants who have noticed reduced balance and their ability to perform the physical exercises

\begin{tabular}{lll}
\hline & No reported problem with balance & Noticed problem with balance \\
\hline Able to perform all the physical exercises & $95 \%(19)$ & $5 \%(1)$ \\
Not able to perform all the physical exercises & $69 \%(11)$ & $31 \%(5)$ \\
\hline
\end{tabular}

Three test participants who were not able to perform all the physical exercises said that they performed the activities with some of the adjustments shown in the videos.

The average score for the questions in the expanded version of the ABC- 6 scale was $91.3 \%$ for participants who could not complete all physical exercises and $94 \%$ for those who could. However, the minimum value for those who passed was lower than for those who could not pass (59\% vs $79.5 \%$, respectively). Both groups included participants who answered that they were $100 \%$ sure that they could perform all the activities without falling. The answers to the expanded ABC-6 scale are summarized in Table 5.

\section{Discussion}

This study shows that the tested physical exercises were useful for self-assessment of physical ability. Early impairment in physical ability could not be identified solely with measurement of body composition, walking speed, questions, videos that show adjustments common in people with impaired balance or an extended version of the ABC- 6 scale.

Health care has no test capable of finding early age-related decreases in physical ability related to fall risk [8]. Most of the age-related decreases in physical ability occur at an age of 60 years [8]. Fall-related injuries in the workplace are most common among workers aged 56-65 years and are also more common among workers aged 46-55 years than among younger workers [3]. Fifty percent of middle-aged people in one study had impaired balance [22]. Therefore, it is important to find a method to help middle-aged people notice that they have decreases in physical ability related to fall risk early so that they can take steps to remedy these decreases. The physical exercises in this study had the possibility to help middleaged people notice decreases in physical ability related to fall risk that they were not aware of before the study.

All test participants in this study had a daily walking speed above $1 \mathrm{~m} / \mathrm{s}$, which is associated with fewer risk factors associated with fall [9]. They were able to perform the balance tests used for elderly persons [17] and to stand with their feet close to each other in a semitandem and a tandem position for $20 \mathrm{~s}$. The test participants were also able to walk in different directions at a speed corresponding to the Four Square Step Test [16] and performed squats at a speed corresponding to the 30 -s chair stand test [18]. Finally, they were also able to take a large step and return to the starting position [19]. Therefore, none of the physical exercises used to identify increased risk of fall in elderly persons could be used to find any reduction of physical ability related to fall risk for any of the test participants. However, six of the test participants reported that they had noticed imbalances such as stumbling on carpets, falling down stairs twice, performing fast movements such as walking sideways, and unsteadiness when stepping up on a chair, trying to reach something high up, and trying to dress and stand on one leg. Five of these test participants failed any of the physical exercises, Table 3.

The self-assessment of balance must be evaluated with a wide range of balance-based questions since none of the test participants claimed that they had problems with balance in daily life. The questions about balance must also address the fact that some persons who perform sport activities notice problems with balance during these activities and thereby report problems even if they might have better physical ability related to fall risk than most others person at their age. With the questions used in this study, 11 persons did not report any problems with balance even if they were not able to perform all the physical exercises, Table 3, and could therefore possess early markers for a risk of falling without knowing it.

When the test participants watched the videos, they were asked to indicate which of the videos best represented how they performed the everyday activity. This question can provide false information about their ability to perform the everyday activity since they might compensate even if they do not need to. It is better to ask both whether they can perform the everyday activity without adjustments and how they usually perform the activity. When watching the videos, some of the

Table 4 Summary of the number of test participants who answered if they performed the activities on the videos with or without adjustment and who could or could not perform the physical exercises

Do activities without adjustment Do the activities with some of the adjustments shown in the videos

Able to perform all the physical exercises

$65 \%(13)$

$35 \%(7)$

Not able to perform all the physical exercises

$19 \%(3)$

$81 \%(13)$ 
Table 5 Summary of the responses to the expanded ABC- 6 scale

Expanded ABC-6 scale

Able to perform all the physical exercises

94\% (59-100\%)

Not able to perform all the physical exercises

test participants realized that they make adjustments even if they do not need to, and some said that they would change their behavior and start to perform the activity without making adjustments. Even some of those who could not perform the everyday activity without making adjustments said that they would start training to be able to perform the everyday activity without making adjustments.

The videos seem to be a better method than oral interview questions for identifying which of the test participants could perform all the physical exercises. This is illustrated in Table 4, where only 3 test participants who were not able to perform all the physical exercises answered that they could perform all the activities in the videos without making adjustments. This is in comparison with the 11 test participants who were not able to perform all the physical exercises who answered in the oral interview questions that they had no problem with balance, Table 3 .

The test participants answered the expanded ABC- 6 scale orally. Some of them claimed that it was difficult to give an answer in terms of percentage. Some who responded with a number less than $100 \%$ added that one can never be sure even if they had never had a problem with the activity. They also said that too many variables were involved to definitively give a score of $100 \%$, such as the slipperiness of the ground and the kind of chair used. In this study, the expanded version of the ABC-6 scale gave no relevant information since both the test participants who were able to perform all the physical exercises and those who were not gave similar answers.

Since all the physical exercises used in the study were based on tests used for elderly persons, the limit for increased risk of fall for elderly persons is known. However, the limit for middle-aged people is difficult to determine since the physical ability in middle age must be good enough to allow a decrease in physical ability not only as a result of aging but also by other circumstances, such as injury and illness.

In this study, the ability to perform quick steps in different directions was the one physical exercise that the test participants most frequently were not able to perform. The limit used may have been set too high, but the fact that some of the test participants spontaneously commented that they were surprised that their feet did not want to move faster suggests that the speed selected was reasonable. The ability to quickly perform steps in different directions seems to be an early indicator of the age-related decrease in physical ability since none of the test participants had failed any of the other physical exercises without failing the quick steps. When losing balance, it is of

importance to be able to quickly regain balance by taking a recovery step. Elderly people have problems with balancing reactions such as rapid stepping or reaching movements that are critical for preventing falls and have difficulty in controlling lateral stability during stepping reactions, which may increase the risk of falling laterally and sustaining a hip fracture [15]. Younger persons often regain balance with one recovery step during forward loss of balance, while elderly people have a shorter recovery step length with less stability [23]. Elderly persons have also shown slower protection steps than younger persons [24]. Therefore, it is important to be able to perform quick steps in different directions. Some quick steps can be included in some daily activities as a strategy to ensure that they will be practiced.

The physical exercises can be used to estimate balance, ability to perform a quick step and leg strength. The instructions the test participants received from the test leader can easily be implemented in a web tool together with questions and videos. The web tool would help the individual become aware of his or her physical ability or if the individual makes unnecessary adjustments when performing daily activities and thereby miss important training in daily life. If the individual is aware of deficits in physical ability related to fall risk, the person can use the knowledge in the web tool and perform the relevant training. If the individual is aware that they are making unnecessary adjustments when performing daily activities, he or she can change this behavior and perform unadjusted daily activities to strengthen the physical ability related to fall risk.

The results from this study indicate the need for further studies in several related directions. One research thread concerns further tests on a larger group to validate the test methodology. For example, the need for physical exercises that can measure core strength and rapid angle torque development in the ankle must be further investigated since the test participants were not able to perform the physical exercises and see for themselves if they had performed the physical exercise correctly. Another research thread concerns the effects of preventing training to decrease the risk of falling and to see if the deterioration is reversible with exercise. A third research thread concerns the implementation of these physical ability tests in the general population.

\section{Conclussion}

In conclusion, this study indicates that a combination of questionnaires, videos and physical exercises can evaluate physical ability and act as a method to identify early markers related to increased fall risk. The questionnaire, videos and physical exercises can be implemented in a web tool that could make persons aware that they have decreased physical ability regarding fall risk or that they needlessly make 
physical compensations when performing daily activities and thus are missing opportunities to strengthen their physical ability every day.

Acknowledgements The authors thanks Vinnova, Sweden and the research profile ESSH+ for financial support for the study.

Funding Open access funding provided by Mälardalen University.

\section{Compliance with ethical standards}

Conflict of interest On behalf of all authors, the corresponding author states that there is no conflict of interest.

Informed consent Informed consent was obtained from all test participants.

Open Access This article is licensed under a Creative Commons Attribution 4.0 International License, which permits use, sharing, adaptation, distribution and reproduction in any medium or format, as long as you give appropriate credit to the original author(s) and the source, provide a link to the Creative Commons licence, and indicate if changes were made. The images or other third party material in this article are included in the article's Creative Commons licence, unless indicated otherwise in a credit line to the material. If material is not included in the article's Creative Commons licence and your intended use is not permitted by statutory regulation or exceeds the permitted use, you will need to obtain permission directly from the copyright holder. To view a copy of this licence, visit http://creativecommons.org/licenses/by/4.0/.

\section{References}

1. Timsina LR, Willetts JL, Brennan MJ, Marucci-Wellman H, Lombardi DA, Courtney TK, Verma SK. Circumstances of fallrelated injuries by age and gender among community-dwelling adults in the United States. PLoS ONE. 2017. https://doi.org/10. 1371/journal.pone.0176561.

2. Guirguis-Blake M, Michael YL, Perdue LA, Coppola EL, Beil TL, Thompson JH. Interventions to Prevent Falls in CommunityDwelling Older Adults: A Systematic Review for the U.S. Preventive Services Task Force [Internet]. U.S. Preventive Services Task Force Evidence Syntheses, formerly Systematic Evidence Reviews. Rockville (MD): Agency for Healthcare Research and Quality (US). 2018;Report No.: 17-05232-EF-1.

3. AFA Försäkring. Fallolyckor March 2018. 2018. https://www. afaforsakring.se/globalassets/forebyggande/analysoch-statistik/ arbetsskaderapporten/ovriga-rapporter-om-arbetsskador-ochsjukfranvaro/f6345_delarapport_fallolyckor.pdf. Accessed 2 Jul 2020.

4. Dionyssiotis Y. Analyzing the problem of falls among older people. Int J Gen Med. 2012;5:805-13.

5. WHO. Global recommendations on physical activity for health. Geneva: World Health Organization. 2010 ISBN: 9789241599979.

6. Sherrington C, Michaleff ZA, Fairhall N, Paul SS, Tiedemann A, Whitney J, Cumming RG, Herbert RD, Close JCT, Lord SR. Exercise to prevent falls in older adults: an updated systematic review and meta-analysis. Br J Sports Med. 2017. https://doi.org/ 10.1136/bjsports-2016-096547.

7. Liu CJ, Latham NK. Progressive resistance strength training for improving physical function in older adults. Cochrane Database
Systematic Reviews. 2009. https://doi.org/10.1002/14651858. CD002759.pub2.

8. WHO. Integrated care for older people, Guidelines on communitylevel interventions to manage declines in intrinsic capacity. Geneva: World Health Organization. 2017; ISBN 978-92- 4-155010-9.

9. Quach L, Galica AM. Jones, RN, Procter-Gray E, Manor B, Hannan MT, Lipsitz LA. The Non-linear Relationship between Gait Speed and Falls: The Maintenance of Balance, Independent Living, Intellect, and Zest in the Elderly of Boston Study. J Am Geriatr Soc. 2011; https://doi.org/10.1111/j.1532-5415.2011. 03408.x.

10. Blake AJ, Morgan K, Bendall MJ, Dallosso H, Ebrahim SB, Arie TH, Fentem PH, Bassey EJ. Falls by elderly people at home: prevalence and associated factors. Age Ageing. 1988;17(6):365-72.

11. Van Ancum JM, Pijnappels M, Jonkman NH, Scheerman K, Verlaan S, Meskers CGM, Maier AB. Muscle mass and muscle strength are associated with pre- and post-hospitalization falls in older male inpatients: a longitudinal cohort study. BMC Geriatr. 2018;16;18(1):116. https://doi.org/10.1186/s12877-018-0812-5

12. Yang NP, Hsu NW, Lin CH, Chen HC, Tsao HM, Lo SS, Chou P. Relationship between muscle strength and fall episodes among the elderly: the Yilan study. Taiwan BMC Geriatr. 2018. https://doi. org/10.1186/s12877-018-0779-2.

13. Peretz C, Herman T, Hausdorff JM, Giladi N. Assessing fear of falling: Can a short version of the Activities-specific Balance Confidence scale be useful? Movement Disorders 2006;21: 2101-2101-5.

14. Schepens S, Goldberg A, Wallace M. The short version of the Activities-specific Balance Confidence (ABC) scale: Its validity, reliability, and relationship to balance impairment and falls in older adults. Arch Gerontol Geriatr. 2010. https://doi.org/10.1016/j. archger.2009.06.003.

15. Maki BE, McIlroy WE. Control of rapid limb movements for balance recovery: age-related changes and implications for fall prevention. Age and ageing. 2006;35-S2, ii12-ii18.

16. Dite W, Temple VA. A clinical test of stepping and change of direction to identify multiple falling older adults. Arch Phys Med Rehabil. 2002;83(11):1566-71.

17. Gardner MM, Buchner DM, Robertson MC, Campbell AJ. Practical implementation of an exercise-based falls prevention programme. Age Ageing. 2001;30(1):77-83.

18. Applebaum EV, Breton D, Feng ZW, Ta AT, Walsh K, Chassé K, Robbins SM. Modified 30-second Sit to Stand test predics fall in a cohort of institutionalized older veterans. PLoS ON. 2017. https:// doi.org/10.1371/journal.pone.0176946.

19. Cho BL, Scarpace D, Alexander NB. Tests of stepping as indicators of mobility, balance, and fall risk in balance-impaired older adults. J Am Geriatr Soc. 2004;52(7):1168-73.

20. Thelen DG, Schultz AB, Alexander NB, Ashton-Miller JA. Effects of age on rapid angle torque development. Journal of Gerontology. 1996;51(5):M226-32.

21. Butowicz CM, Ebaugh DD, Noehren B, Silfies SP. Validation of two clinical measures of core stability. Int J Sports Phys Ther. 2016;11(1):15-23.

22. Ekblom B, Engström LM, Ekblom OB. Secular trends of physical fitness in Swedish adults. Scand J Med Sci Sports. 2007;17:267-73.

23. Carty CP, Mills P, Barrett R. Recovery from forward loss of balance in young and older adults using the stepping strategy. Gait Posture. 2011. https://doi.org/10.1016/j.gaitpost.2010.11.017.

24. Lee PY, Gadareh K, Bronstein AM. Forward-backward postural protective stepping responses in young and elderly adults. Hum Mov Sci. 2014. https://doi.org/10.1016/j.humov.2013.12.010.

Publisher's note Springer Nature remains neutral with regard to jurisdictional claims in published maps and institutional affiliations. 